\title{
MIXED CORE SUBCHANNEL MODEL FOR SUBCAL AND COUPLING WITH ANDREA
}

\author{
VOJTĚCH CAHA ${ }^{a, b, *}$, JIŘí ČížEK ${ }^{b}$ \\ a Department of Nuclear Reactors, FNSPE, CTU in Prague, V Holešovičkách 2, Prague, Czech Republic \\ ${ }^{b}$ Chemcomex, a.s., Elišky Přemyslovny 379, Prague, Czech Republic \\ * corresponding author: vojtech.caha@fjfi.cvut.cz
}

\begin{abstract}
This paper presents the results of an analysis of flow distribution in VVER-1000 mixed core consisting of fuel assemblies with non-identical spacing grids. The calculation was carried out using the modified subchannel code SUBCAL-AZ which allows to calculate 3D thermal-hydraulic characteristics of the coolant flow in the full core subchannel model coupled with the neutron-physical code ANDREA. This full core subchannel model was created in three variants depending on the ANDREA calculations. The first variant (homogeneous core) consisted of 163 hydraulically identical fuel assemblies TVSA-T mod.2, whereas the other variants (mixed cores) consisted of fuel assemblies TVSA-T mod.0, mod.1 and mod.2. These fuel assemblies mainly differ in types, number and axial coordinate of spacing grids and also in diameter of guide tubes. The influence of mixed core to flow distribution was obtained by comparing these variants.
\end{abstract}

KEYWORDS: subchannel analysis, SUBCAL, mixed core, code coupling, VVER-1000.

\section{INTRODUCTION}

When a reactor core consists of more than one type of fuel assembly, the flow redistributions due to differences in fuel assembly pressure drops may be introduced. The crossflow, as well as the axial flow, results in flow-induced coolant temperature changes and thus may influence a heat generation in a fuel rod. The mixed core can also cause that a flow penalty may be applied with respect to the homogeneous reference core in detail stand-alone fuel assembly subchannel calculation where lateral flow and turbulent mixing between fuel assemblies is not considered. An important aspect of core performance evaluation is the ability to predict interchange transfer of mass and energy. Two mechanisms are identified: crossflow and thermal mixing. Crossflow involves net transfer of the coolant (both mass and energy) between assemblies or subchannels. Thermal mixing is energy exchange due to a radial enthalpy gradient with no associated net mass transfer. Modified subchannel thermal-hydraulic code such as SUBCAL-AZ [1], 2] can be used to account for the effects of crossflow in fuel assemblies and reactor cores due to hydraulic mismatch or power gradient, and perform the more accurate coolant temperature or density distribution. More accurate results can be used as input for neutron-physical codes to improve their results or licensing applications for example.

The thermal-hydraulic subchannel code SUBCAL is developed in Chemcomex and used in the nuclear industry in Czech Republic for VVER core design, licensing applications and safety assessments of fuel cycles 3 . SUBCAL was developed based on the COBRA code series. Similar to other subchannel codes currently used for PWR and VVER analyses, SUB-
CAL predicts the three-dimensional velocity, pressure, and thermal energy fields and fuel rod temperatures for single- and two-phase flow in PWR or VVER. SUBCAL solves the finite difference equations for mass, energy, axial and lateral momentum conservation for an interconnected array of channels, assuming incompressible and thermally expandable homogeneous coolant flow. Although the formulation is homogeneous, empirical models are incorporated into the code to account for subcooled boiling and vapor/liquid slip in two-phase flow.

The SUBCAL code was validated and standardized by SÚJB (Nuclear Regulatory Body of the Czech Republic) in 2018 for TVSA-T mod.0/1/2 and LTA fuel (Westinghouse VVER-1000 fuel).

The ANDREA macro code 4 is a program developed in ÚJV Řež since 2005. It serves for calculations of reload design and safety analyses of VVER reactors. The program is also standardized by SÚJB for analyses of reactors VVER-1000.

The program solves a two-group diffusion equation with help of contemporary nodal method which ensures sufficient accuracy and speed of calculations. It enables to work with an arbitrary axial nodalization, the calculations can be carried out in one sixth of a reactor core or in a full core manner.

\section{Core Subchannel MOdeL}

The rough subchannel code SUBCAL-AZ for the entire VVER-1000 core allows the modeling of all 163 assemblies following the neutron-physical calculation by the ANDREA. The subchannel code SUBCAL is used to calculate local coolant parameters in individual assemblies and axial nodes. Single and also mixed 
core fuel cycles can be evaluated. The paper describes a mixed core model composed of TVSA-T mod.0, mod.1 and mod.2 fuel assemblies. Following the offline coupling of the SUBCAL-AZ and ANDREA codes, three cycles calculations were performed by iterative approach. After two to three iterations, the power and temperature distributions have stabilized.

The full core subchannel model was created by connecting 163 separate TVSA-T fuel assemblies where the subchannels of these fuel assemblies were merged together and hence the new types of subchannels were created, i.e. one subchannel represents one fuel assembly. The schematic drawing of the model is shown in Figure 1. The main characteristics of the full core model are listed in Table 1 The axial length and nodalization were taken from previous neutronphysical calculation of power distribution by the code ANDREA [5]. A non-uniform axial nodalization into 204 nodes was used at total length of $3730 \mathrm{~mm}$, thus each node was within range 10.8 to $19.2 \mathrm{~mm}$. For the purposes of assessing the influence of the mixed core on the coolant flow and temperature distribution, three variants of the core load were created. The first variant consisted of 163 hydraulically identical fuel assemblies TVSA-T mod.2 (homogeneous core), while the other variants (mixed core) were composed of 48 and 97 fuel assemblies TVSA-T mod.2 and 115 and 66 fuel assemblies TVSA-T mod.0/1 (Figure 2 and Figure 3). The fuel assemblies TVSA-T mod.1 and mod.2 differ, for the purpose of subchannel code calculation, in particular in the number and types of spacing grids and the diameter of the guide tubes. There are also other differences but these do not affect subchannnel calculation. All types of spacing grids are shown in Table 2 and their coefficients of resistance can be found in $[2$.

Different types of spacing grids for TVSA-T mod.1 and mod.2 fuel assemblies are associated with different turbulent mixing coefficients values. For mod.2 fuel assemblies, the value of the turbulent mixing coefficient $\beta_{1}$ is given along the entire axial length, while mod.2 fuel assembly is divided into two axial parts. A value of $\beta_{2}$ is taken into account up to the first mixing grid (Type 1 - approx. $2500 \mathrm{~mm}$ ), whereas the second part has a turbulent mixing coefficient equal to $\beta_{3}>\beta_{2}$. All turbulent mixing coefficients were carefully set up on the basis of mixing experiments for stand-alone fuel assemblies [6]. At the interface between mod.1 and mod.2 fuel assemblies, the mean value is considered. The axial geometry of spacing grids for both types of fuel assemblies is shown in Figure 4

\section{SUBCAL-AZ AND COUPLING WITH ANDREA}

SUBCAL-AZ is a computational code consisting of the subchannel code SUBCAL and Python structure designed to automatically process data from the neutronphysical code ANDREA output files and transform them into input files of the SUBCAL code. Thus,

\begin{tabular}{lc}
\hline Parameter & Number [-] \\
\hline Subchannels & 163 \\
\hline Boundaries & 444 \\
\hline Rods & 163 \\
\hline Axial nodes & 204 \\
\hline TABLE 1. Core subchannel model.
\end{tabular}

\begin{tabular}{cl}
\hline Type & TVSA-T \\
\hline T1 & Mod.2 \\
\hline T2 & Mod.2 \\
\hline T3 & Mod.2 \\
\hline T4 & Mod.1 \\
\hline T5 & Mod.1 \\
\hline T4 & Mod.0 \\
\hline T5 & Mod.0 \\
\hline
\end{tabular}

TABLE 2. Types of spacing grids.

described computational complex SUBCAL-AZ is the thermal-hydraulic part of the off-line coupling of the SUBCAL and ANDREA codes. All necessary parameters such as axial nodalization, core map (position of fuel assemblies in the core), power distribution or regime parameters are assumed from ANDREA output files. In comparison with the neutron-physical code ANDREA the subchannel calculation requires finer axial nodalization due to rapid changes of flow behind spacer grids, hence it was considered four times finer axial nodalization (ANDREA - 51 axial nodes, SUBCAL - 204 axial nodes). The power distribution is loaded from the ANDREA output files as node pin power and merged to node assembly power and then transformed to SUBCAL numbering and saved to input files. Another regime parameters, which are also taken over, are system pressure, inlet temperature or inlet flow. After SUBCAL calculation, in addition to standard output files, a SUBCAL-ANDREA file containing matrices of selected parameters (linear power, mass flow, coolant temperature and coolant density) prepared for input to the ANDREA computation is created.

\section{Results}

There were evaluated three variants (cycles) with different number of TVSA-T mod. 2 fuel assemblies to obtain flow distribution in the core. The most important parameter which was observed is the average mass flow $[\mathrm{kg} / \mathrm{s}]$ in fuel assemblies with respect to the type of fuel assembly. This parameter could be later used for more accurate subchannel calculations of stand-alone fuel assemblies in mixed core as inlet flow. Figures 5, 6 and 7] show axial dependence of 


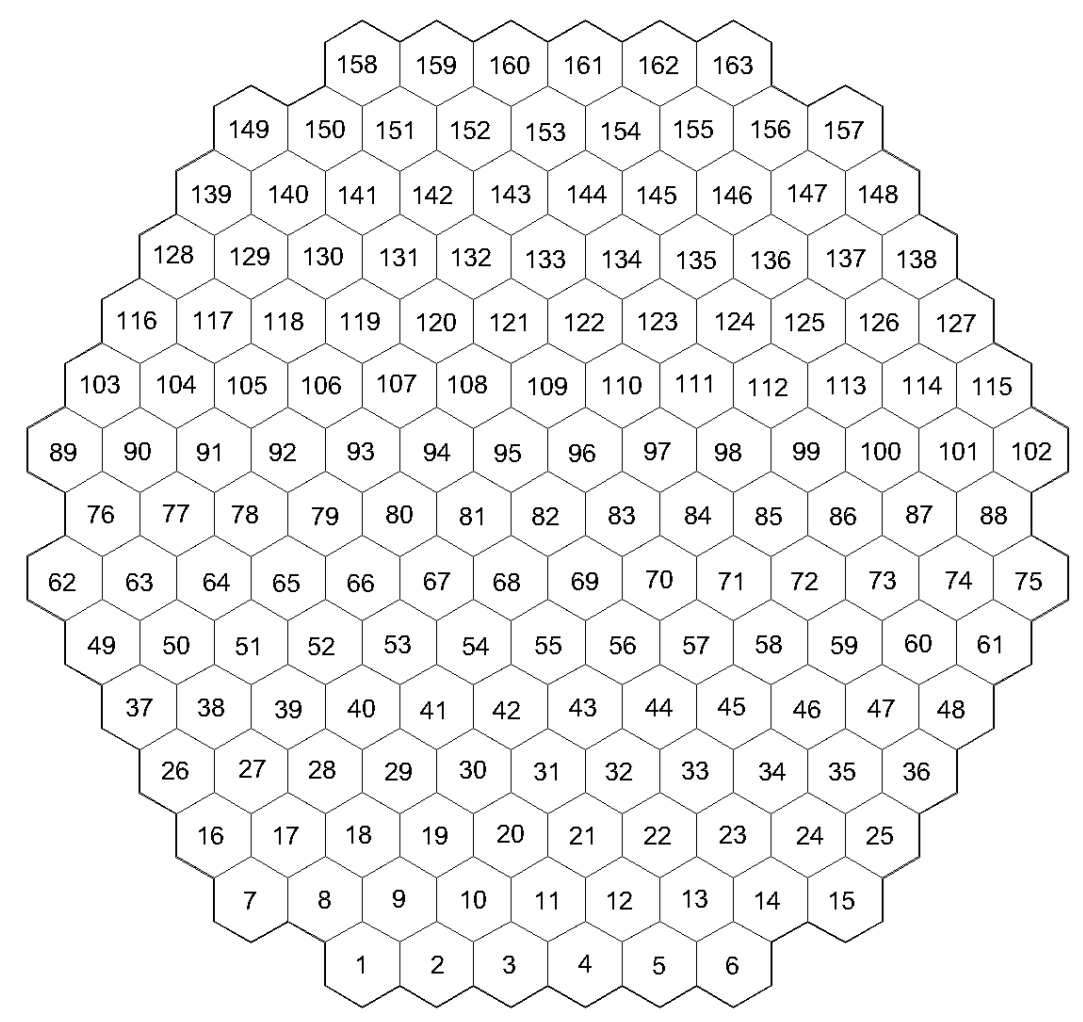

FIGURE 1. Core subchannel model with subchannel (fuel assemblies) numbering.

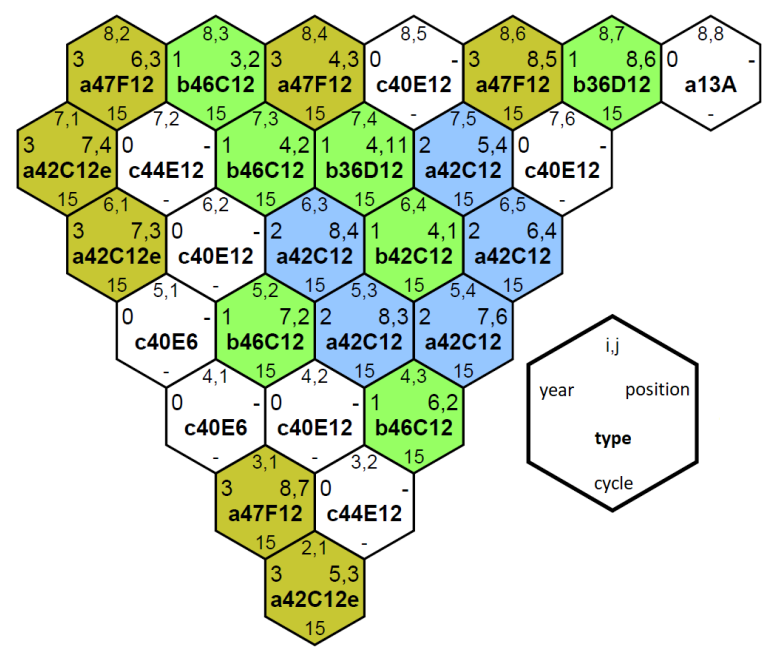

Figure 2. Mixed core u2c16. [5]

mass flow in several fuel assemblies and axial position of spacer grids and its resistance coefficients. The fuel assemblies (subchannels) were chosen as a representative set for given fuel cycle - the sets differ because of different fuel assemblies in the core positions, see Figures 1, 2 and 3. The flow rate in homogeneous core (Figure 5) depends mostly on power of fuel assembly and its position in the core, the average flow rate is for all fuel assemblies almost the same. Axial changes of flow rate are gradual and in narrow range. Whereas, the average flow rate in mixed cores strongly depends also on the type of fuel assembly,

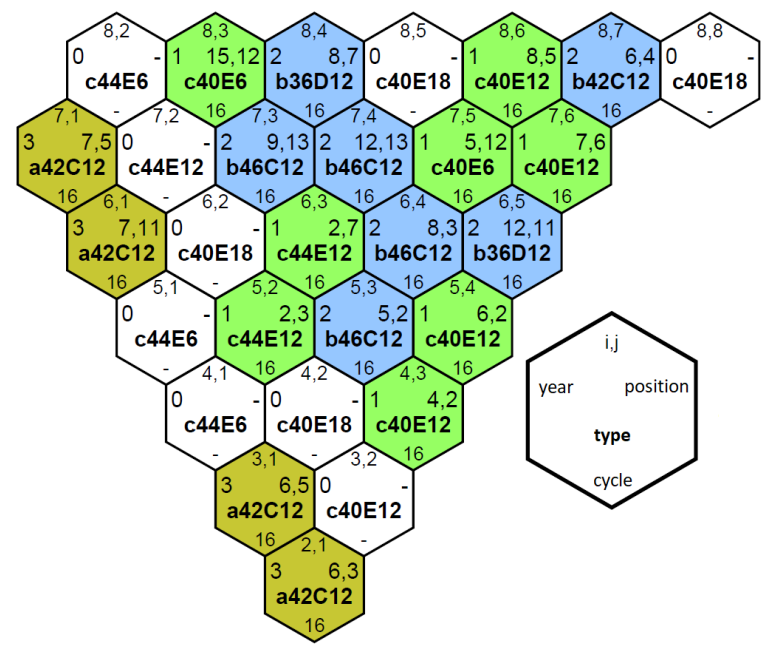

Figure 3. Mixed core u2c17. [5]

their resistance coefficient and flow area. Axial dependence of the flow rate is also influenced by position and type of spacer grids in fuel assembly itself and neighboring fuel assemblies. We can observe rapid changes of flow rate immediately behind spacer grids induced by lateral flow. The decrease in average flow rate is the most significant in fuel assemblies with higher resistance coefficient surrounded by more fuel assemblies of other type. This decrease could reach up to $4 \%$ in calculated fuel cycles.

The manufacturer of the fuel assemblies (TVEL) provides a simple formula (Equation 1) to estimate 


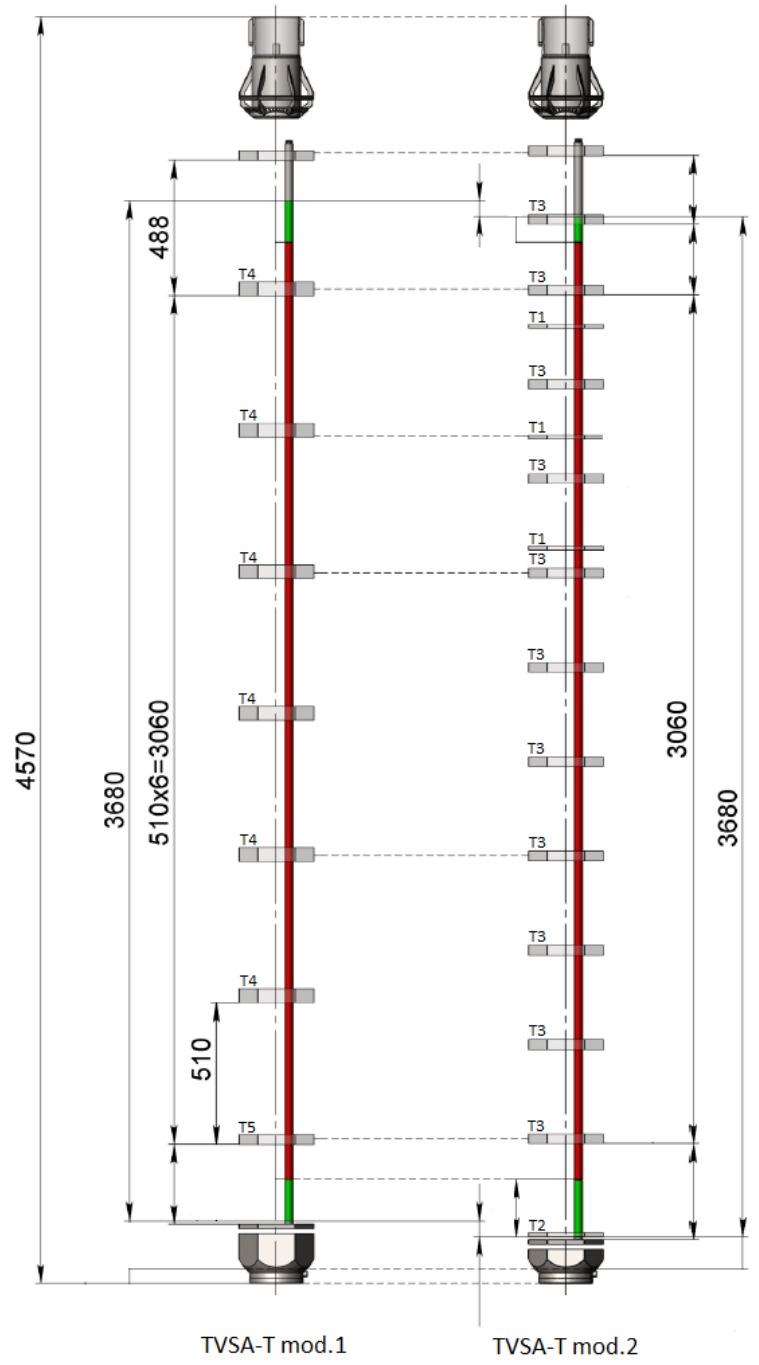

Figure 4. Axial geometry of TVSA-T mod.1/2.

the change of flow rate in mixed cores. It depends only on number of two types of fuel assemblies and their resistance coefficients and flow areas. Subchannel calculations found a good agreement of average flow rate in given type of fuel assembly and flow reduction from Equation 1] [2].

$$
G_{\text {mod } .1}=\frac{N_{\text {mod.1 }}+N_{\text {mod.2 }}}{N_{\text {mod.1 }}+N_{\text {mod. } 2} \frac{S_{\text {mod. } 2}}{S_{\text {mod.1 }}} \sqrt{\frac{\xi_{\text {mod.1 }}}{\xi_{\text {mod. }}}}}
$$

where:

$G_{\text {mod.1 }}=$ Relative flow rate in TVSA-T mod.1

$N_{\text {mod.1 }}=$ Number of TVSA-T mod.1 in the core

$N_{\text {mod.2 }}=$ Number of TVSA-T mod.2 in the core

$S_{\text {mod.1 }}=$ Flow area of TVSA-T mod.1

$S_{\text {mod.2 }}=$ Flow area of TVSA-T mod.2

$\xi_{\text {mod.1 }}=$ Resistance coefficient of TVSA-T mod.1

$\xi_{\text {mod.2 }}=$ Resistance coefficient of TVSA-T mod.2

\begin{tabular}{cccc}
\hline \multicolumn{4}{c}{ Iteration error [\%] } \\
\hline Time [DDD:HH:MM:SS] & $\mathbf{1 - 2}$ & $\mathbf{2 - 3}$ & $\mathbf{3 - 4}$ \\
\hline 000:00:00:00 & 1.045 & 0.068 & 0.005 \\
002:00:00:01 & 1.035 & 0.069 & 0.006 \\
005:00:00:02 & 0.964 & 0.069 & 0.006 \\
010:00:00:03 & 0.866 & 0.056 & 0.006 \\
030:00:00:04 & 0.863 & 0.053 & 0.004 \\
050:00:00:05 & 0.844 & 0.067 & 0.003 \\
070:00:00:06 & 0.777 & 0.061 & 0.004 \\
090:00:00:07 & 0.710 & 0.052 & 0.003 \\
110:00:00:08 & 0.689 & 0.045 & 0.002 \\
130:00:00:09 & 0.704 & 0.043 & 0.002 \\
150:00:00:10 & 0.707 & 0.044 & 0.002 \\
170:00:00:11 & 0.711 & 0.044 & 0.002 \\
190:00:00:12 & 0.576 & 0.043 & 0.002 \\
210:00:00:13 & 0.502 & 0.026 & 0.002 \\
230:00:00:14 & 0.373 & 0.018 & 0.002 \\
250:00:00:15 & 0.333 & 0.042 & 0.002 \\
270:00:00:16 & 0.304 & 0.037 & 0.007 \\
290:00:00:17 & 0.297 & 0.034 & 0.005 \\
310:00:00:18 & 0.284 & 0.034 & 0.004 \\
317:00:00:19 & 0.310 & 0.034 & 0.004 \\
347:00:00:20 & 0.000 & 0.000 & 0.000
\end{tabular}

TABLE 3. Linear power assembly node $[\mathrm{W} / \mathrm{cm}]$ iteration error - u2c17.

The second goal of this work was to provide an off-line coupling of the subchannel code SUBCAL and the neutron-physical code ANDREA and replace simple model of isolated channels for evaluation of moderator/coolant temperature or density. The most significant changes were observed in power distribution and an example of iteration error is shown in Table 3 for several states during one year fuel cycle. All calculations showed that three or four iterations are needed to achieve final results.

\section{Conclusions}

Whereas the ANDREA code contains a TH module that calculates coolant heating only for fuel assemblies by isolated channel method, where pressure or turbulent lateral flow between subchannels (fuel assemblies) is not considered, the calculations were performed with the SUBCAL-AZ code, which involves both pressure and lateral flow. The off-line coupling of SUBCAL and ANDREA allows to evaluate the methodical error of the isolated channel method. There were performed three different core loads - mixed and homogeneous cores.

The ANDREA code calculated the nodal pin power distribution, while the subchannel code SUBCAL provided local flow, temperature and density of coolant in each subchannel and axial node. The temperature and density distribution from the SUBCAL was again used in the ANDREA to calculate power distribu- 


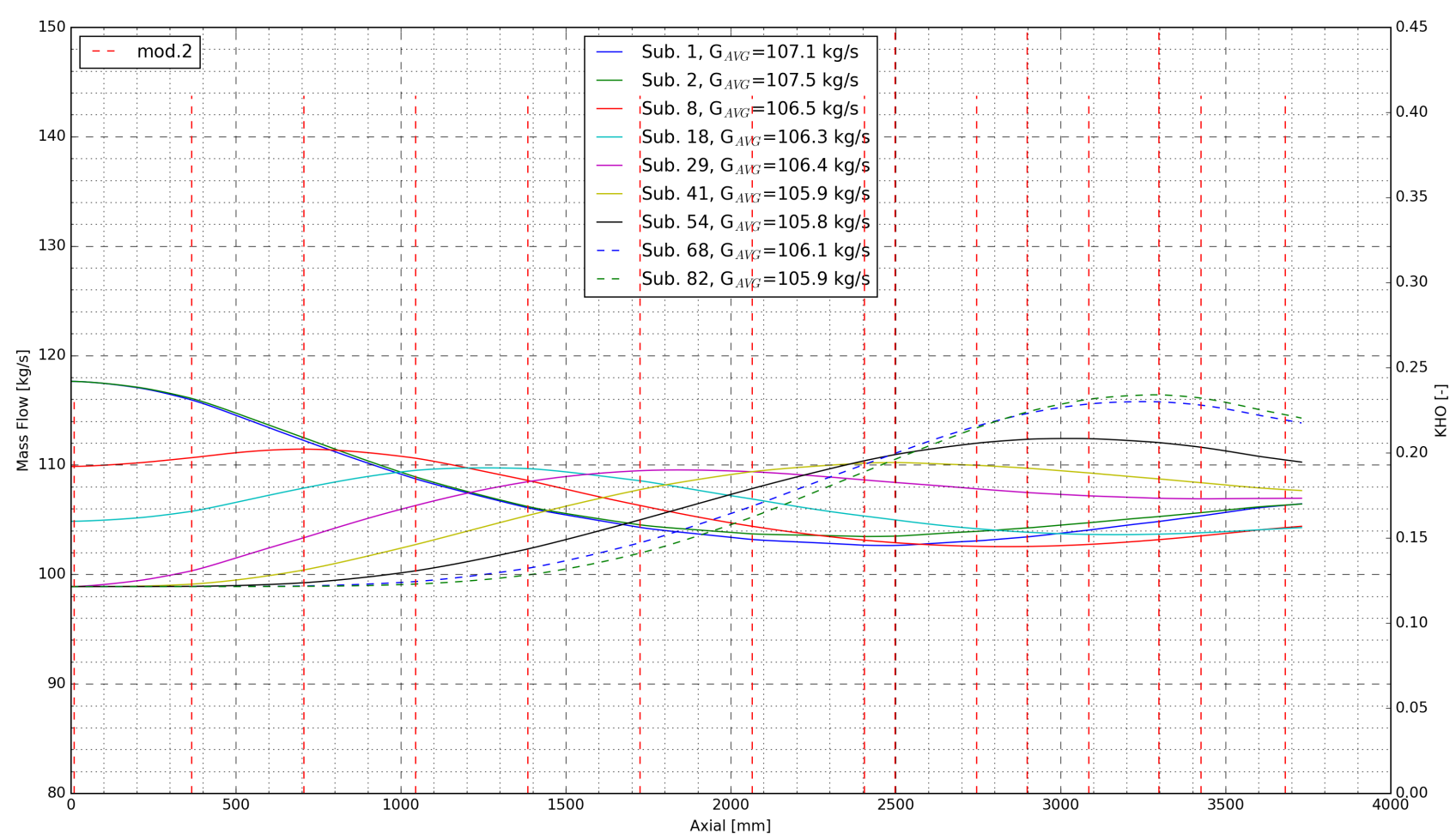

Figure 5. Mass Flow in homogeneous core - 163 TVSA-T mod.2.

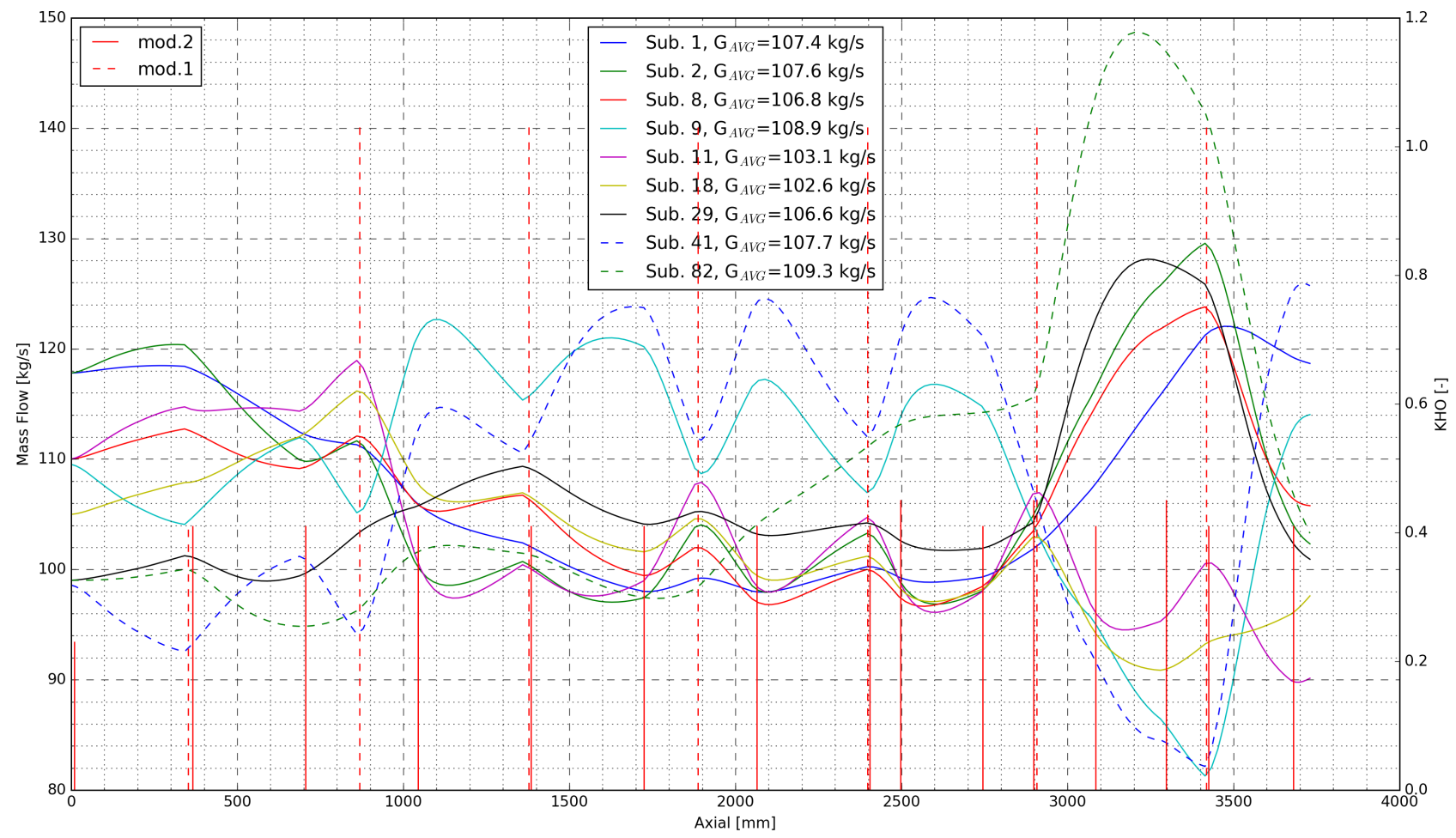

Figure 6. Mass Flow in u2c16 - 48 TVSA-T mod.2. 


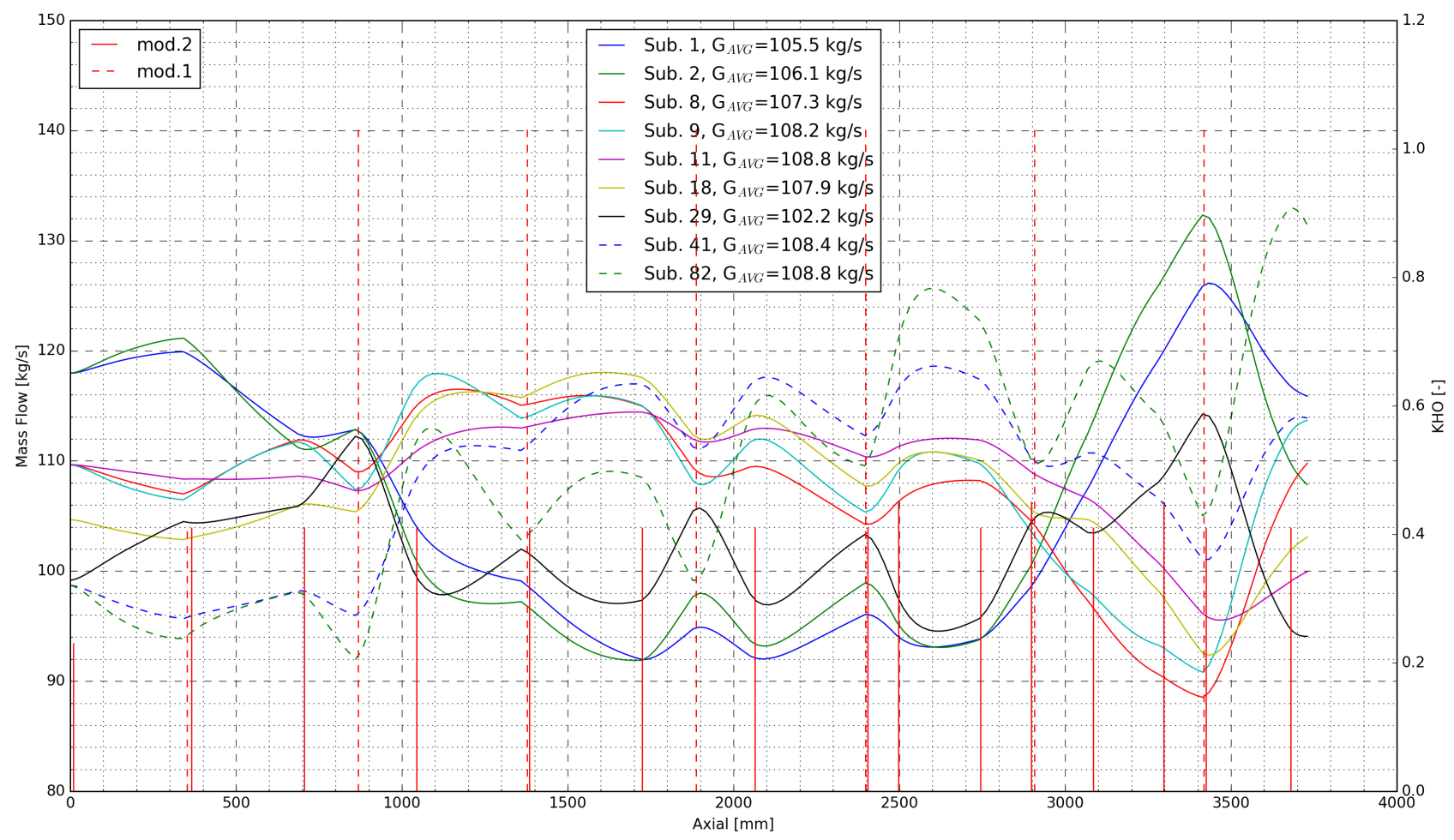

Figure 7. Mass Flow in u2c16 - 97 TVSA-T mod.2.

tion. After three or four iterations, the power and temperature distribution have stabilized.

In conclusion, TH calculations using the ANDREA isolated channel method do not affect the power and temperature distribution for homogeneous cores. On the contrary, the mixed core power distribution and axial offset are significantly influenced by used method. 7]

The error of linear power node calculation caused by neglecting of lateral flow and turbulent mixing (isolated channel method) could reach more than $1 \%$ in mixed cores.

The subchannel calcultaion of flow rate in fuel assemblies is important part of new type fuel assemblies licensing loaded in mixed cores and safety assesment of fuel cycles.

\section{REFERENCES}

[1] J. Č́žzek, V. Caha. SUBCAL-ETE Dokumentace programu, Rev. 1, 108064.00.093.85\%. Chemcomex, 2018.

[2] J. Čížek. Stanovení průtoku v palivových souborech směsné AZ složené z TVSA-T mod.0/1 a LTA, Rev. 0, ÚJV-ORF-2018-005. ÚJV Řež, 2018.

[3] J. Čížek, V. Caha, J. Krejčí. 01-TH Metodika bezpečnostního hodnocení palivových vsázek, Rev. 4, 108368.171437. Chemcomex, 2017.

[4] J. Hejzlar, R. Vočka. Kvalifikace výpočetního programu ANDREA v2.2, Rev. 0, UJV-Z-4484. ÚJV Řež, 2016.

[5] J. Hejzlar. ANDREA Mixed core calculation: Cycles u2c16 and u2c1\%. ÚJV Řež, 2018.

[6] V. Caha, J. Čížek. SUBCAL-ETE Koeficient turbulentního mišení: TVSA-T mod.2, Rev. 0, 00.432.179. Chemcomex, 2016.

[7] J. Hejzlar. Propojení programů ANDREA a SUBCAL, Rev. 0, ÚJV-ORF-2018-017. ÚJV Řež, 2018. 